\title{
Fire safety of complex buildings (tall buildings, tunnels, subways, etc.)
}

\author{
Jie Ji' (凹), Anthony Hamins², Simo Hostikka ${ }^{3}$, Mehdi Jangi ${ }^{4}$, Futoshi Tanaka ${ }^{5}$, Long Ding' \\ (Guest Editors) \\ 1. State Key Laboratory of Fire Science, University of Science and Technology of China, JinZhai Road 96, Hefei, Anhui 230026, China \\ 2. National Institute of Standards and Technology, 100 Bureau Dr., Gaithersburg, MD, USA \\ 3. Department of Civil Engineering, School of Engineering, Aalto University, Rakentajanaukio 4A, 02150 Espoo, P.0. Box 12100, 00076 Aalto, \\ Finland \\ 4. School of Mechanical Engineering, University of Birmingham, Edgbaston, Birmingham, B15 2TT, UK \\ 5. Mechanical Engineering, Faculty of Engineering, University of Fukui, 3-9-1 Bunkyo, Fukui-shi, Fukui, 910-8507, Japan
}

(c) Tsinghua University Press 2022

Urbanization has accelerated over the last few decades. An increasing number of complex structures, such as high-rise buildings, city underground tunnels, and subways, are being built to relieve the increasing pressure of traffic congestion and inefficient use of urban space. Significant attention has been paid to the fire safety of these complex structures because of many disastrous fire accidents reported worldwide. For instance, the Grenfell Tower fire (2017) in London caused 72 deaths, the high-rise apartment fire (2010) in Shanghai caused 58 fatalities, and the Beijing Television Cultural Center fire (2009) resulted in an economic loss exceeding 588 million USD. Complex buildings have created significant, unique fire safety challenges, owing to their super large and complex configurations, the use of novel materials, complex human evacuation procedures, and fire safety precautions.

Because of the spatial particularity of complex buildings, the fire spread characteristics, personnel evacuation strategy, and fire early warning technology of complex buildings must be different from those of traditional buildings. Therefore, a topical issue titled "Fire Safety of Complex Buildings (Tall Buildings, Tunnels, Subways, etc.)” was proposed and implemented to investigate the problems existing in complex building fires and reduce losses caused by complex building fires. After a thorough peerreview process, 14 outstanding papers were accepted for publication in Building Simulation.

The building types in this issue include tunnels (4 papers), subway trains (1 paper), and civil buildings
(5 papers). In one study, artificial intelligence (AI) technology was applied to the real-time prediction of tunnel fires. This study demonstrated the promising prospects of AI-based real-time fire forecasting and provided an example for applying smart firefighting technologies in tunnel spaces. Valuable findings are also reported in several other papers on tunnel fires. For example, the study on branch tunnel fires showed that the enlarged cross-sectional area in a branch tunnel shortened the back-layering length. In addition, a modified model of the back-layering length was established. The fire smoke spread characteristics of complex buildings are the basis of smoke control. Three papers reported smoke spread characteristics based on atrium buildings, solar roofs, and urban buildings and presented many interesting research conclusions. For example, a study on the fire smoke spread of solar roofs showed that the roof slope significantly impacted the spread of fire smoke. When designing a solar roof, fire smoke protection and photovoltaic (PV) energy performance should be considered, particularly in low-latitude regions where the PV optimal title angle regarding energy performance is small increasing smoke infiltration risks. A study investigated fire reconstruction, an effective method for studying tall building fires. Collecting the evidence for the structural response analysis provides a novel methodology for carrying out forensic investigations of tall building fires, which can guide structural and fire engineers in improving structural fire safety and life safety designs.

E-mail: jijie232@ustc.edu.cn 
Moreover, four papers reported the evacuation in complex buildings, established the evacuation and pedestrian motion models, and analyzed the influence of the geometric structure of complex buildings on the evacuation process. These studies provide a reference for formulating personnel safety evacuation strategies for complex buildings.

Overall, the papers published in this issue show significant differences in fire development and smoke spread between complex and traditional building fires. The proposed fire real-time prediction technique, pedestrian motion model, and evacuation model are valuable in ensuring the fire safety of complex buildings and minimizing fire losses. This topical issue is just a start, and significant work is still required to make these advanced techniques more robust, reliable, and affordable to achieve their large-scale applications. 